\title{
Mechanical Properties Evaluation of the Carbon Fibre Reinforced Aluminium Sandwich Composites
}

\author{
Uthirapathy Tamilarasan ${ }^{a, b} *$, Loganathan Karunamoorthy ${ }^{b}$, Kayaroganam Palanikumar \\ ${ }^{a}$ Department of Production Engineering, Sri Sairam Engineering College, \\ Chennai-44, Tamil Nadu, India \\ ${ }^{b}$ Department of Mechanical Engineering, Anna University, Chennai-25, Tamil Nadu, India \\ ${ }^{c}$ Department of Mechanical Engineering, Sri Sai Ram Institute of Technology, \\ Chennai-44, Tamil Nadu, India
}

Received: July 2, 2015; Revised: July 28, 2015

\begin{abstract}
Sandwich laminates play an important role in industries and they are used in varieties of engineering applications. In the present investigation, carbon fiber reinforced aluminium sandwich laminates are fabricated and their properties such as tensile, flexural and impact are studied for their use in structural applications. All the tests are carried out as per ASTM standard. Scanning Electron Microscope (SEM) analysis is carried out to investigate the structure of the sandwich laminates. The microstructures clearly indicate the fractured surface. The tested specimen clearly indicates the fracture surface of the sandwich composites.
\end{abstract}

Keywords: carbon fiber, aluminium alloy, sandwich laminates, mechanical properties, SEM analysis

\section{Introduction}

The composite materials are used in many engineering applications due to their excellent properties. The sandwich composite materials replace the metals owing to their excellent strength with low weight. Many of the literature deals with the combination of steel or aluminium reinforced with the glass fiber reinforced composites materials (GFRP). The carbon fiber finds application in aerospace and related fields. The cost of fabrication is reduced by using sandwich structures. The aluminium is sandwiched between the carbon layers formed as fiber metal laminates (FML), and it has excellent qualities such as overall reduced weight, corrosion resistance and environment friendly. Along with the host of benefits, the main disadvantage is the fabrication of these composites which is difficult ${ }^{1}$. The aircraft materials are developed based on fiber metal laminates which needs the improved crack growth properties ${ }^{2}$. Competing materials like advanced aluminium alloys and fibre reinforced composites have potential to increase the cost effectiveness of the structure. Fibre metal laminates (FMLs) have hybrid composite structures based on thin sheets of metal alloys and plies of fibre reinforced polymeric materials ${ }^{3}$.

The fibre/metal composite technology combines the advantages of metallic materials and fibre reinforced matrix systems. Metals are isotropic because they have a high bearing strength and impact resistance and are easy to repair. Full composites have an excellent fatigue characteristic and have high strength and stiffness. The fatigue and corrosion characteristics of metals and the low bearing strength, impact resistance and reparability of composites have overcome by the combination of metal and fibers ${ }^{4,5}$. These material systems

*e-mail: tamilarasan.u@gmail.com are created by bonding composite laminate plies to metal plies $^{6}$. The concept is usually applied to aluminium with aramid and glass fibres, also it is applied to other constituents ${ }^{7}$. Several articles have shown that, FMLs possess both the wonderful impact resistance characteristics of metals and the attractive mechanical properties of fiber reinforced composite materials ${ }^{8-10}$. Carbon fiber reinforced plastic (CFRP) is a high strength-to-weight and stiffness-to-weight ratio materials and they have been widely used in many fields such as aircraft, aerospace, ship, etc. Since the CFRP has more advantages than aramid fiber reinforced plastic (AFRP) and glass fiber reinforced plastic (GFRP), it is used as a potential composite layers to fabricate GLARE. GLARE is a material consisting of alternating layers of thin metal sheets and thin composite layers. High stiffness of carbon fiber provides more efficient crack bridging aluminium layers than aramid fiber and glass fiber. The presence of aluminium layer provides good impact resistance. This combination of high stiffness and strength with good impact resistance gives GLARE a great advantage as an application to the structures of aircraft, space, helicopter, robot, laminated pipe, drive shaft and so on ${ }^{11-14}$. Jiang et al. ${ }^{15}$ have studied the fabrication and characterization of the carbon-aluminium thermal management composites. Lihong et al. ${ }^{16}$ have studied the microstructure and mechanical properties of 1050/ 6061 laminated composite processed by accumulative roll bonding. They have indicated that the 1050 layer shows coarse structure when compared to the 6061 layer. George et al. ${ }^{17}$ have studied the mechanical response of carbon fiber composite sandwich panels with pyramidal truss cores. They have studied the failure modes and analysed the structures. Sun et al. ${ }^{18}$ have studied the carbon fiber aluminium foam sandwich with short aramid 
fiber interfacial toughening. Caprino et al. ${ }^{19}$ have studied the low velocity impact behavior of glass fiber reinforced plastics aluminium sandwich composite materials. Khalili et al. ${ }^{20}$ have studied the mechanical properties of Steel/Aluminium/GRP Laminates and presented in detail. Afaghi-Khatibi et al. ${ }^{21}$ have studied the mechanical behaviour of fiber reinforced metal laminates (FRMLs). They have also studied the fracture behavior of fiber reinforced metal laminates. From the above research studies, it has been asserted that the carbon fiber reinforced aluminium sandwich composite materials are one of the important class of materials and are used in many applications.

In the present investigation, carbon fiber reinforced aluminium composite materials are fabricated and their mechanical properties are evaluated. The fracture surfaces of the materials are evaluated by using scanning electron microscope (SEM).

\section{Experimental}

\subsection{Materials}

In the present investigation, carbon fibre is used for the fabrication of composite materials. The carbon fibre used in the investigation is purchased from the local market in India. For fabricating the composite materials, epoxy resin is used as the matrix. The properties of aluminium used in the present investigation are presented in Table 1. The specification of fiber and resin used in this investigation is presented in Table 2 .

In the present investigation, carbon fibre is used as reinforced fibre material, epoxy resin is used as a matrix and aluminium (AA6061-T6) is used as sandwich plate. The aluminium sandwich carbon fibre laminate is fabricated by means of hand lay-up technique at room temperature. The schematic illustration of the aluminium sandwich carbon fiber reinforced plastic composite specimen is presented in Figure 1.

The Sandwich of Aluminium/Carbon is processed using hand layup technique at the room temperature and the volume fraction of 55:45 ratio is maintained throughout the process to complete one laminate using bi-directional layer of (0-90-0-90-0-AA6061-0-90-0-90-0) carbon fibre and aluminium (AA6061T3) sandwich. Carbon fibre and adhesive has not been bonded properly on the plane surface of the aluminium. Therefore, the inverted roots are made on the aluminium plate in order to fabricate the sandwich composites to avoid the debonding and to have a strong bonding between fibre and aluminium. The specimen is made to the size of $300 \mathrm{~mm} \times 300 \mathrm{~mm} \times 10 \mathrm{~mm}(1 \times \mathrm{b} \times \mathrm{t})$. The test specimen are prepared as per ASTM standard.

\section{Mechanical Testing}

\subsection{Tensile test}

The sandwich carbon fibre reinforced aluminium composite material is fabricated as explained above and it is cut into the required shape and dimension using a saw cutter. The edges of composite specimen are finished by using emery paper. The tensile test specimen are prepared according to the ASTM standard as used by many researchers ${ }^{22-29}$. The process of tensile testing involves fixing the specimen in the machine using proper fixing equipment and the tensile load is applied till the fracture occurs. The tensile force is recorded with respect to the increase in gauge length. The tensile test is carried out on the universal testing machine (make: FIE 11/98-2450). The experiment is repeated for several times. The prepared specimen as per ASTM standard and the fractured specimen after the application of tensile load are presented in Figure 2.

Table 1. Properties of aluminium used in the preparation of sandwich composites.

\begin{tabular}{|c|c|c|c|c|c|c|c|}
\hline $\begin{array}{l}\text { Sl. } \\
\text { No. }\end{array}$ & Material & Density, g/cc & $\begin{array}{c}\text { Modulus of } \\
\text { Elasticity, GPa }\end{array}$ & $\begin{array}{c}\text { Tensile } \\
\text { strength MPa }\end{array}$ & $\begin{array}{c}\text { Yield Strength } \\
\mathrm{MPa}\end{array}$ & $\begin{array}{c}\text { Fatigue } \\
\text { Strength, } \\
\mathrm{MPa}\end{array}$ & Poisson ratio \\
\hline 1 & AA6061-T6 & 2.70 & 68.9 & 310 & 276 & 96.53 & 0.33 \\
\hline
\end{tabular}

Table 2. Specification of fiber and resin.

\begin{tabular}{cc}
\hline Fiber: Carbon & Resin: epoxy \\
\hline 200 gsm & Manufacturer: CIBA GEIGY \\
$2 \times 2$ carbon fiber fabric & Product: Araldite LY556 (Bisphenol - a epoxy resin) \\
& Hardener: HT 972 (aromatic amine hardener) \\
\hline
\end{tabular}
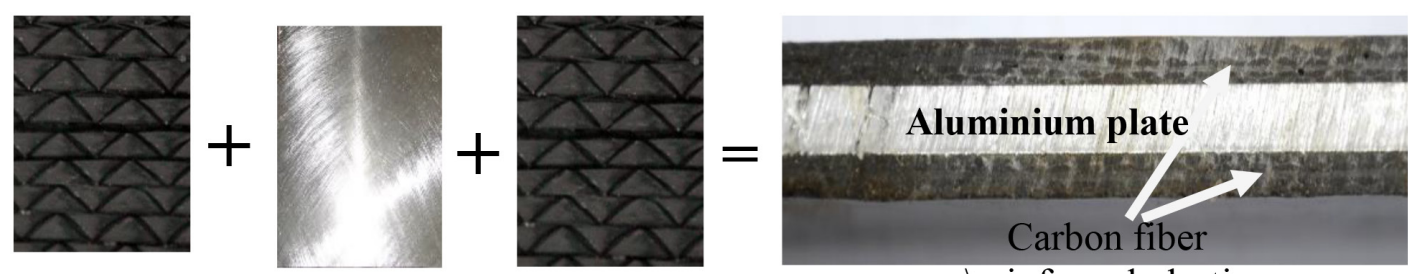

Ireinforced plastic

Figure 1. Schematic illustration of aluminium sandwich carbon fiber reinforced composites. 


\subsection{Flexural test}

The flexural test is carried out using flexural specimen which is prepared as per ASTM standard. The experiments are conducted by using three point flexural tests and it is the most common test method used for composite materials. The deflection of the specimen is measured by means of cross head position. The displacement and the flexural strength are measured. The specimen prepared for conducting the flexural test and the fractured specimen after the testing are presented in Figure 3. The experiments are carried out at a temperature of around $25^{\circ} \mathrm{C}$ with $50 \%$ humidity.

\subsection{Impact test}

The impact test specimen are prepared as per the required dimension specified by ASTM standard. In the testing process, the specimen is fixed in the impact testing machine and the energy is applied by means of an impact load, until the fracture occurs on the specimen. The impact test is used to measure the energy required for breaking the materials.
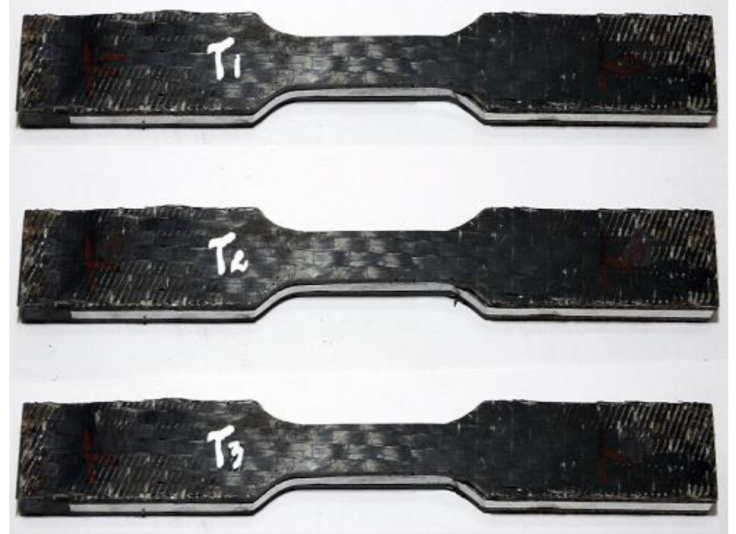

(a)
The specimen used for conducting the impact test and the fractured specimen are presented in Figure 4.

\section{Results and Discussion}

In the present paper, carbon fiber reinforced aluminium sandwich composite materials are used for the investigation. The metal used is aluminium, whereas carbon fiber is used as reinforcing materials with epoxy matrix. The experimental results recorded for the tensile, flexural and the impact loading for the sandwich structure is presented and discussed in the following sections.

The tensile strength analysis for the sandwich composite structure for different specimen is presented in Figure 5. The figure indicates the variation between 283 to $316 \mathrm{MPa}$. The variation is due to the variation that takes place during the fabrication process.

Figure 6 shows the typical curve obtained for tensile strength with respect to stroke and load. The curve indicates that, the tensile load carrying capacity increases up to certain

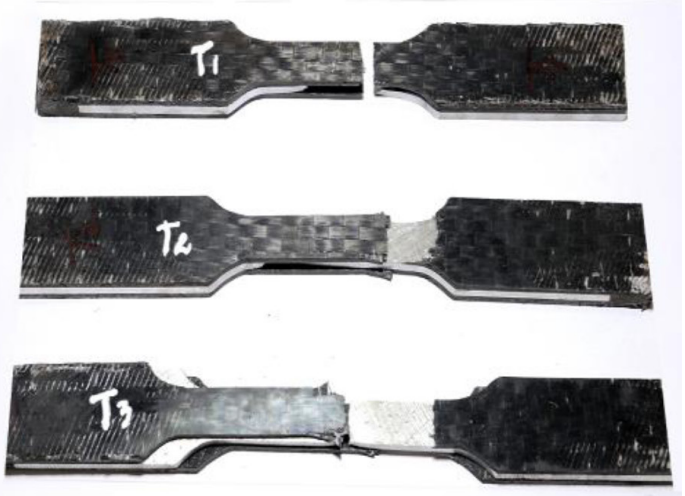

(b)

Figure 2. The specimen before tensile test (a), and after the fracture (b).
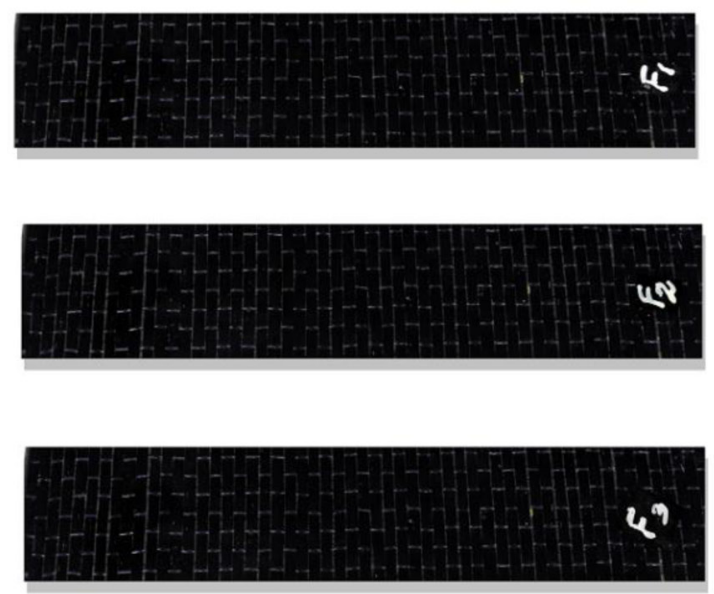

(a)

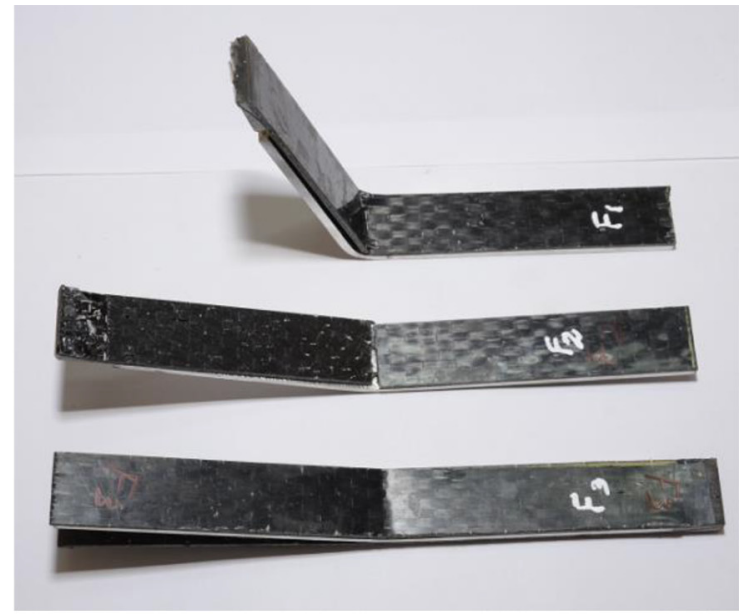

(b)

Figure 3. Specimen for flexural test (a), and the specimen after the flexural test (b). 
extent and after that there is a sudden fall in load later, it moves as a straight line as shown in the figure.

Figure 7 shows the flexural strength for carbon fibre reinforced sandwich laminates. The figure indicates that, there is a variation in load with respect to the stroke and the load carrying capacity. The load carrying capacity increases up to certain limit. After the breaking of aluminium, it tends to fall and the load is maintained almost constant.
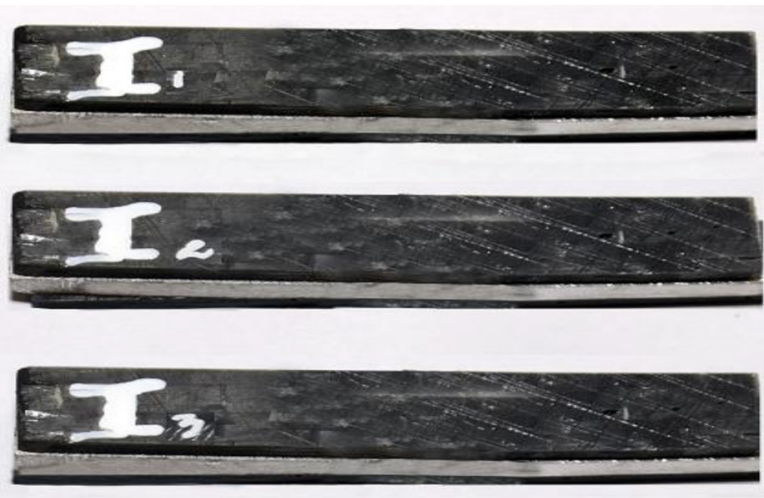

(a)

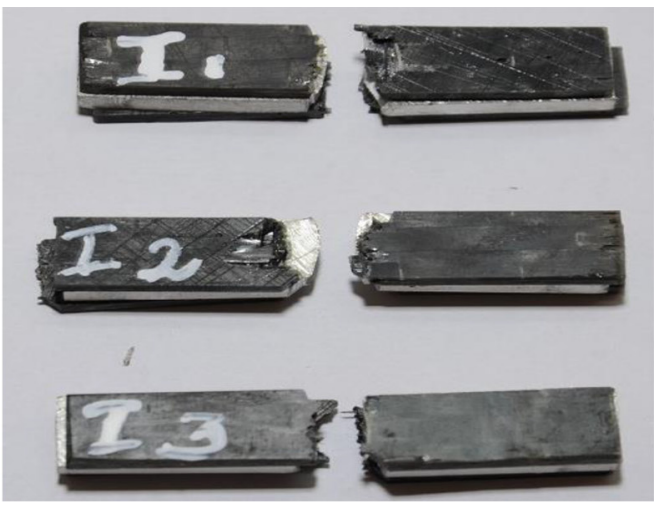

(b)

Figure 4. Izod test specimen before testing (a) and after the testing (b).

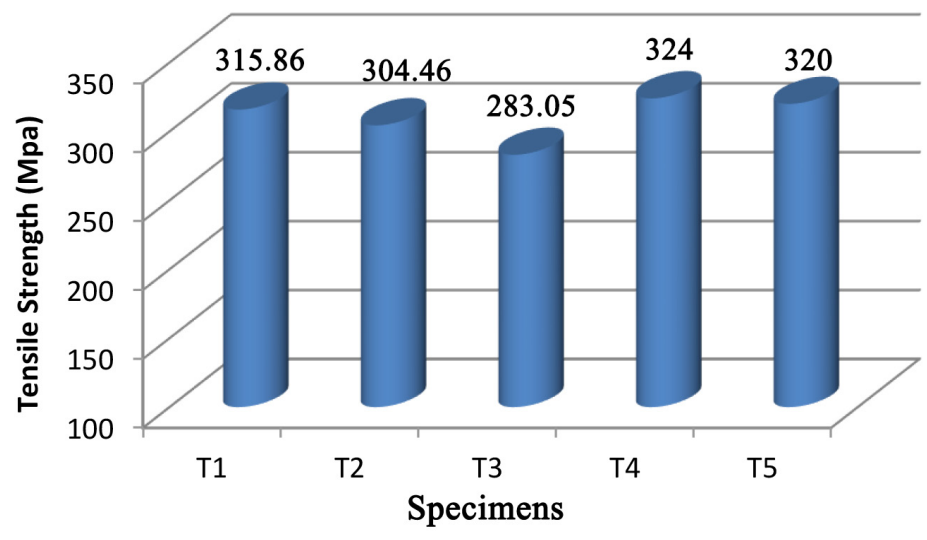

Figure 5. Tensile strength observed for different specimen.

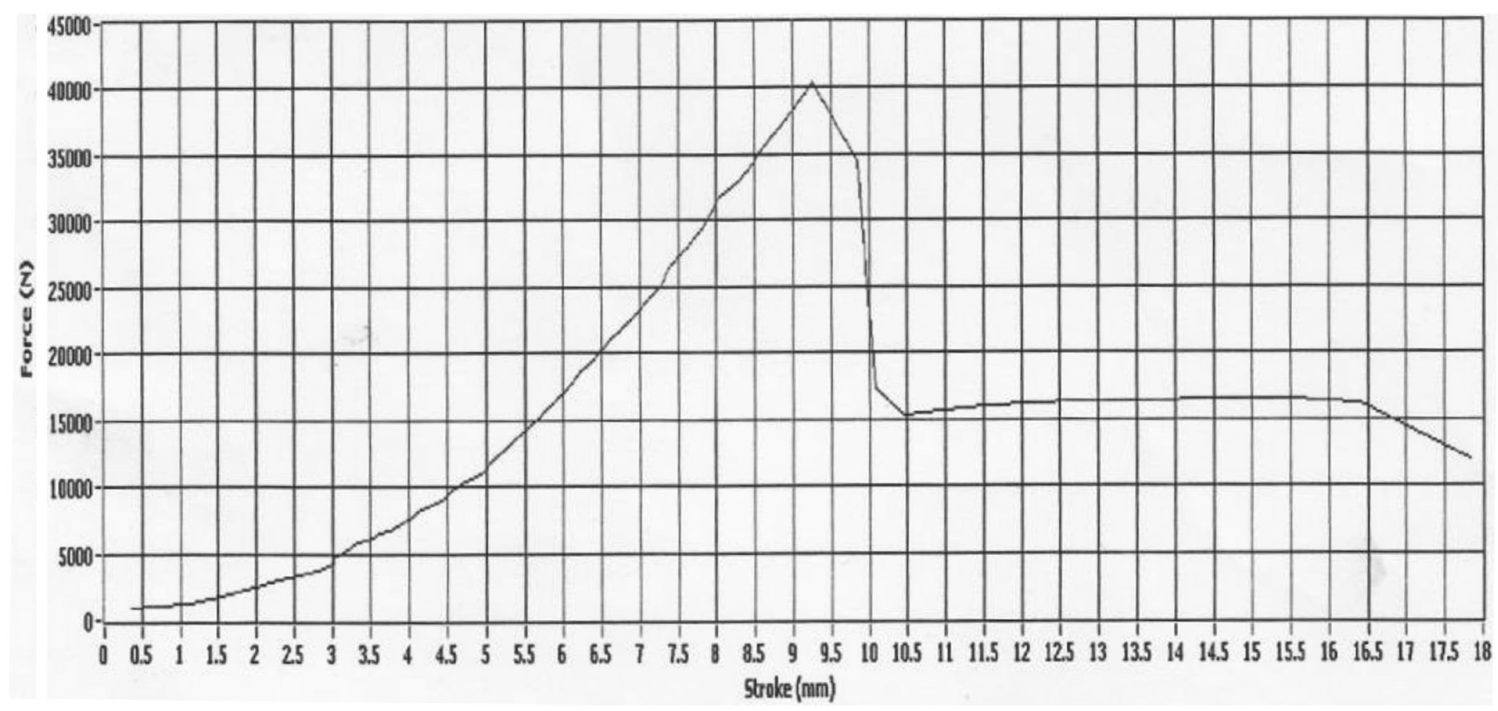

Figure 6. Typical curve observed in tensile test. 
The variation of the fluxural strength with respect to different specimen is presented in Figure 8. A variation in the flexural strength is obtained with respect to the variation in specimen. But the variation is within the limit.

The charpy impact test is carried out on different specimen for finding the impact energy absorbed by the composite samples, which is shown in Figure 9. The figure shows that the energy observation for different samples is almost the same. The variation obtained is very minimal.

The specimen used for the mechanical testing of carbon fiber reinforced sandwich composite is analyzed by using Scanning Electron Microscope (SEM) JEOL JSM-6480LD. The SEM image observed for the sample subjected to the tensile loading is presented in Figure 10.

The figure clearly indicates the broken structure of the tensile specimen. The top layer indicates the structure of the carbon fiber. Due to the application of the load, shearing takes place on the fiber, which shows the fuzzy surface and there is a protruding fiber observed on the specimen. The figure also indicates the fiber pull-out. In the figure, there is a pit formed due to the application of the tensile load. The middle layer indicates the aluminium, which is sheared due to the application of the tensile load. On the specimen, there is a pit and inconsistency in the microstructure. The bottom structure of the specimen indicates the variation in the surface when compared to the top layer. The figure clearly shows the deformed fiber reinforced structure.

The SEM image of the carbon fiber reinforced sandwich laminates subjected to the flexural test is presented in Figure 11. The figure clearly indicates the microstructure of the carbon fibre and the aluminium matrix. The figure has indicated that, there is a cavity formed during the flexural

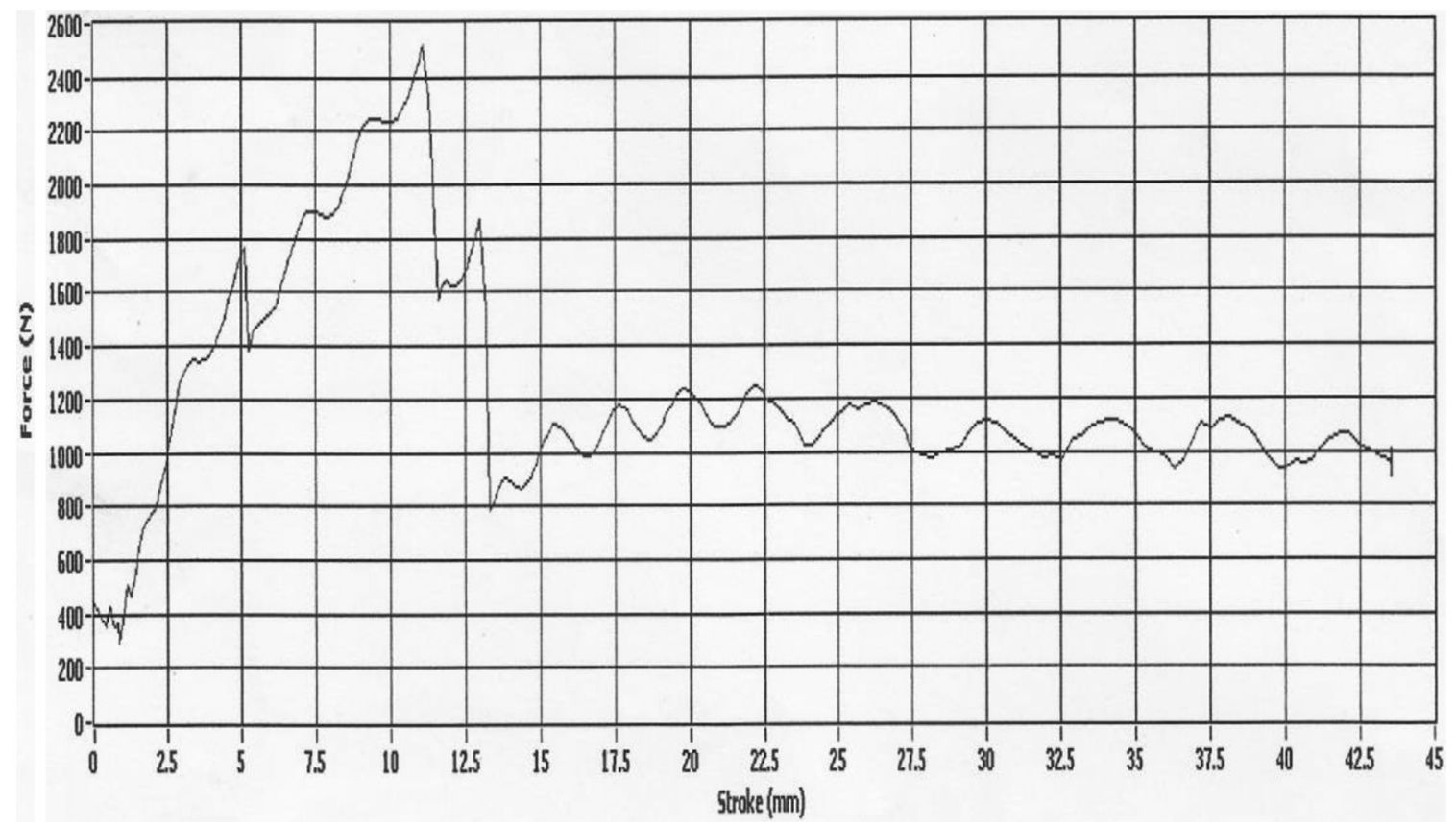

Figure 7. Typical flexural strength curve observed for sandwich laminates.

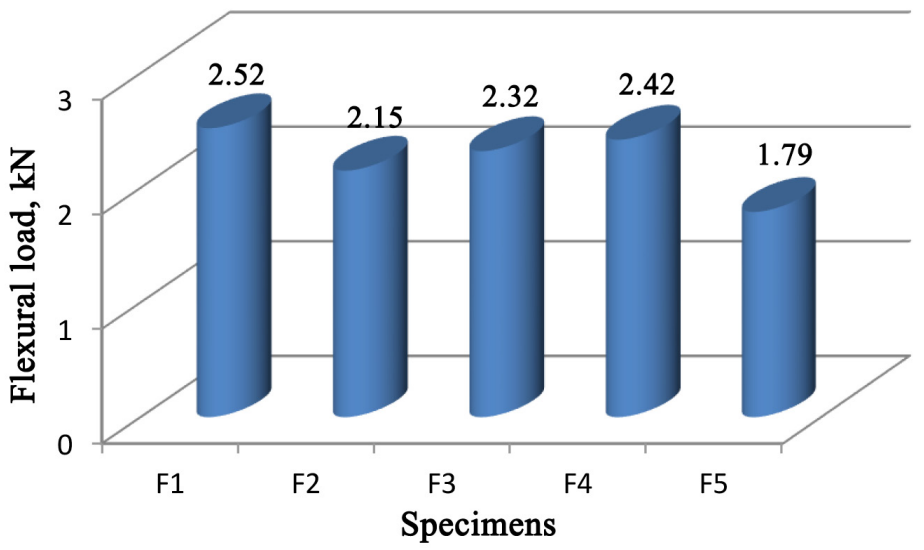

Figure 8. Flexural strength obtained for different specimen. 


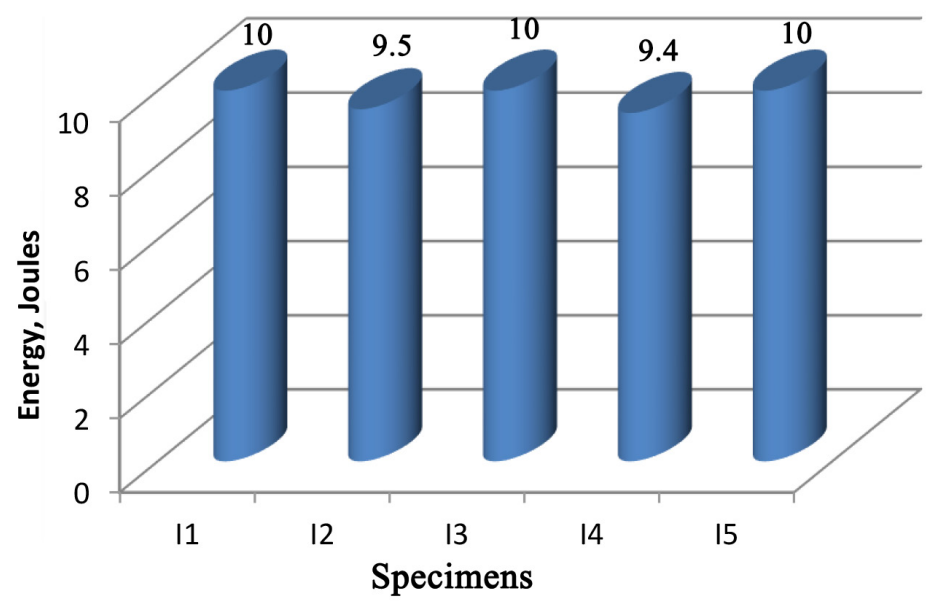

Figure 9. Impact test result for different specimen.

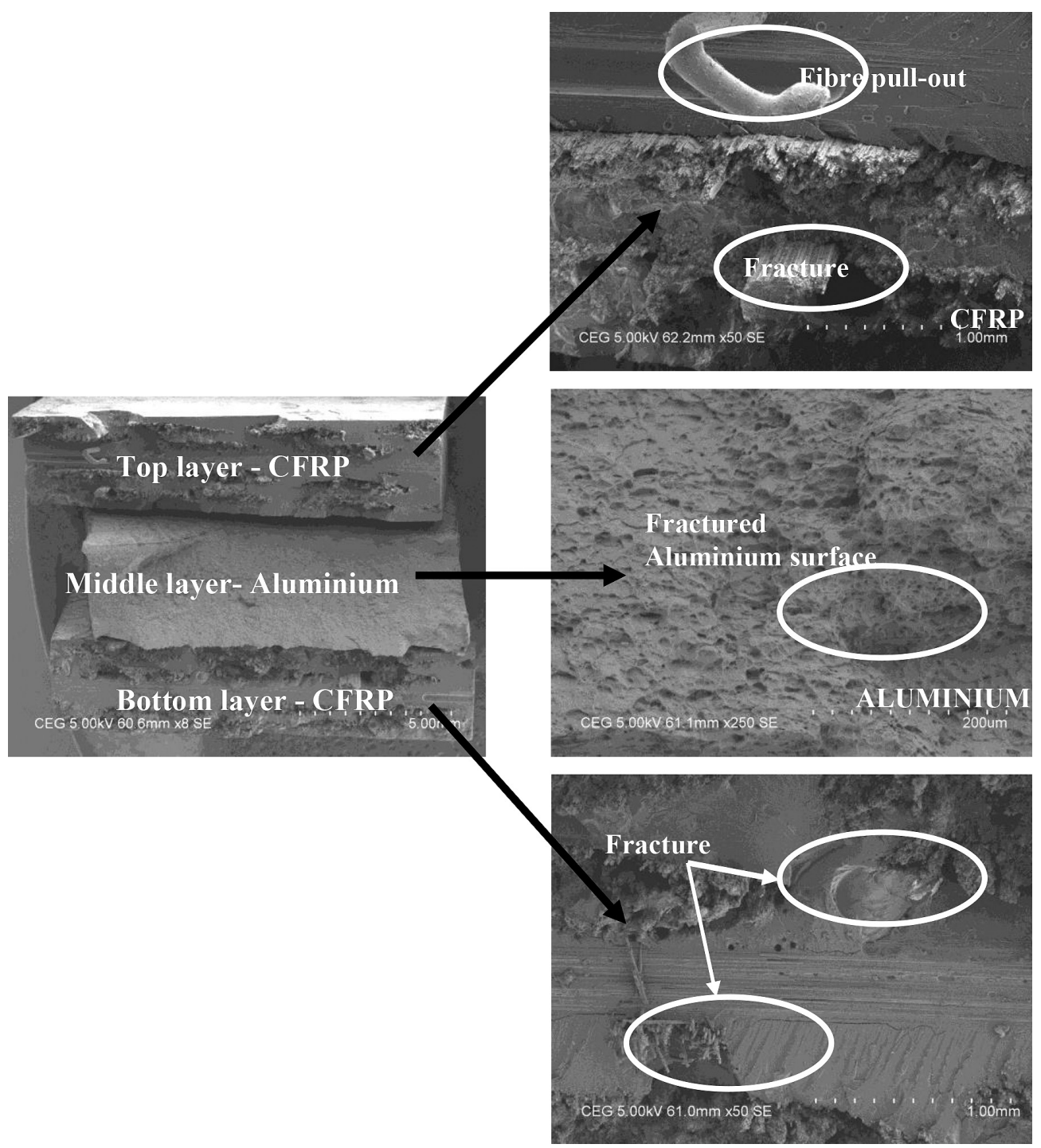

Figure 10. Fractured surface of the tensile specimen. 

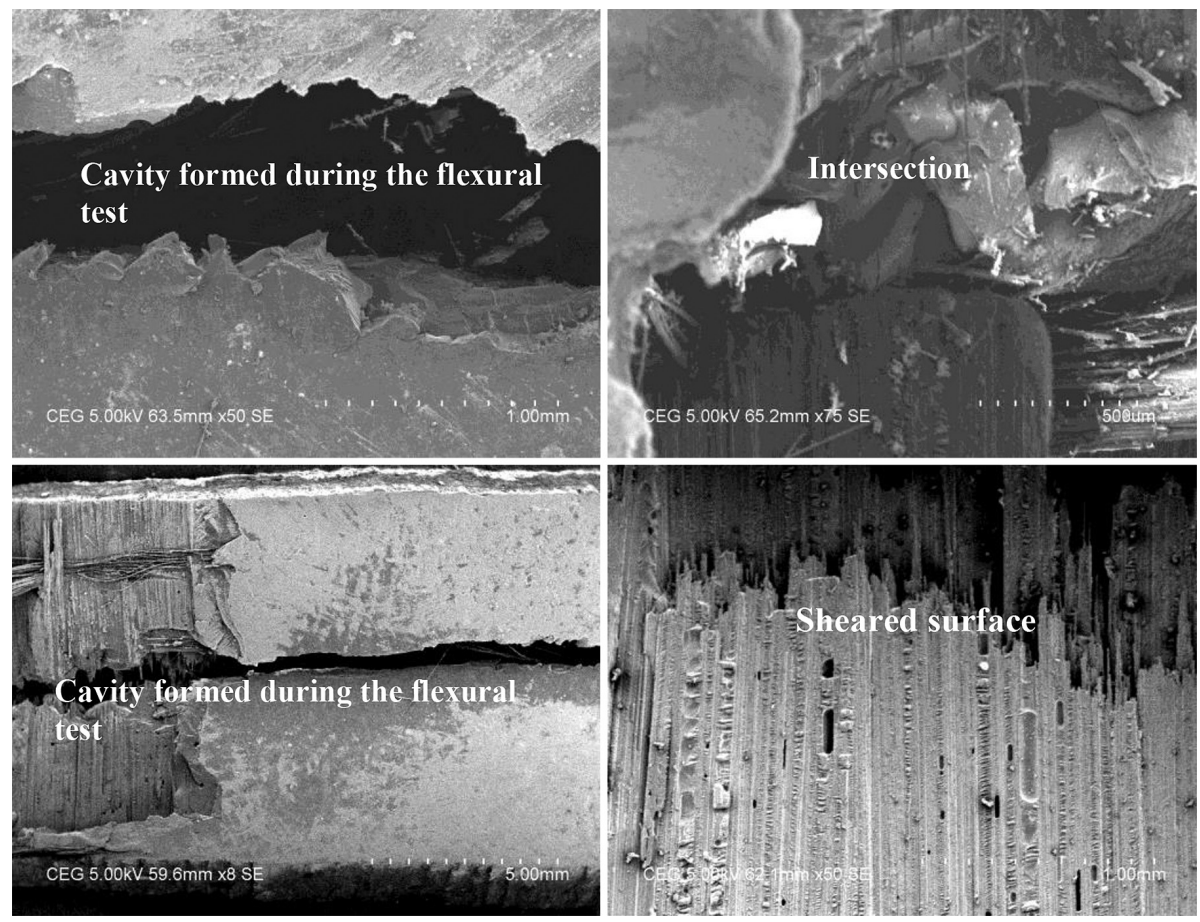

Figure 11. SEM micrograph of the flexural specimen 3 after the test.

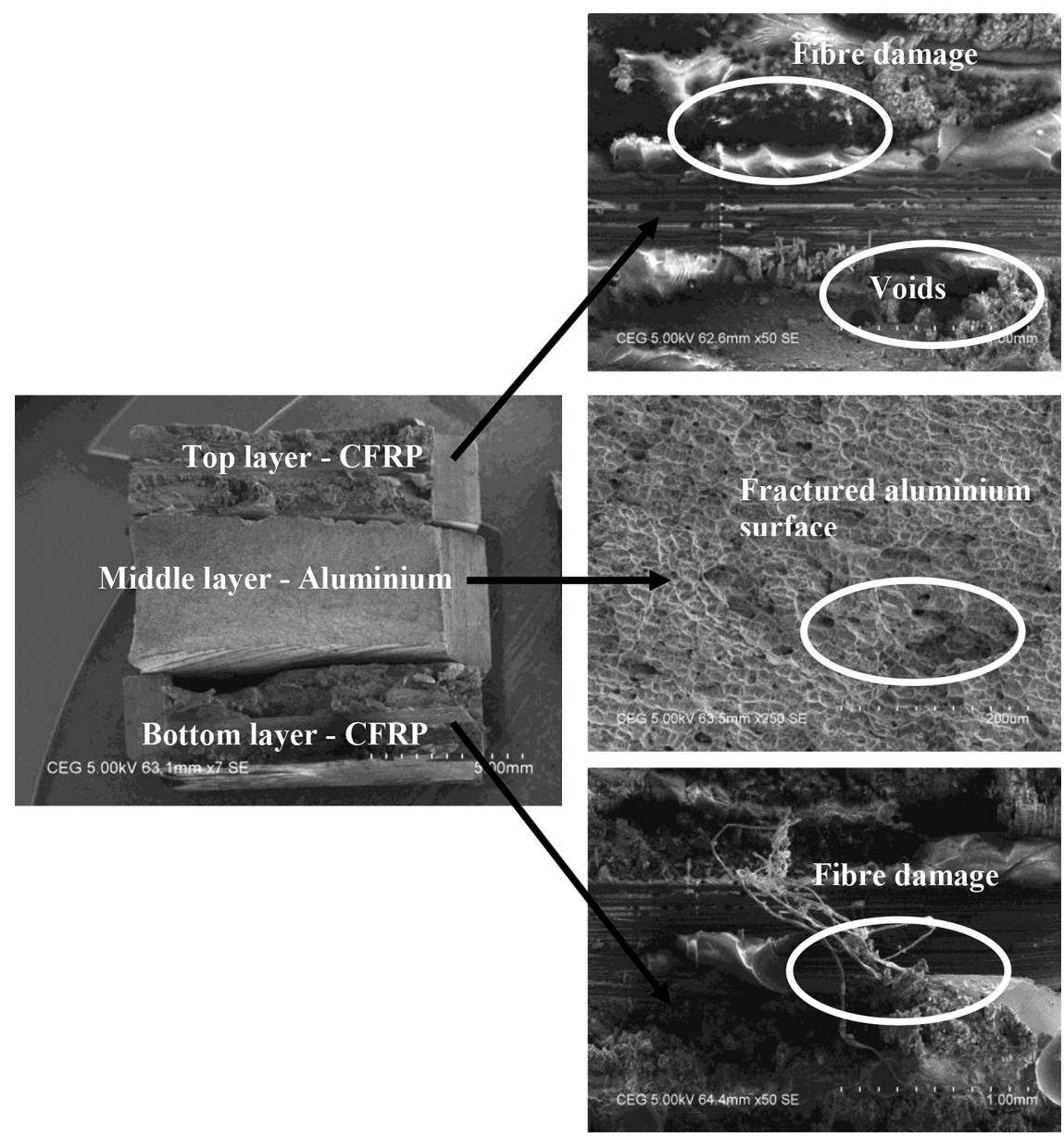

Figure 12. SEM micrograph of the impact specimen after the test. 
test. Also, there is a variation in structure, which is formed due to the application of flexural load. The intersection shows the elongated structure of the laminates. The sheared structure has been shown in the figure.

The SEM image of the carbon fiber reinforced composite specimen subjected to the impact loading is shown in Figure 12. Like the previous figures (Figure 10), the top layer, middle layer and the bottom layers are presented in the figure. When compared to the bottom and middle layer, the top layer deformation is different. In the top layer, the carbon fiber and epoxy matrix are sheared as shown in the figure. Fiber damage and debonding are observed in the top layer of the specimen. Also, there is a void observed on the specimen due to the application of the impact load. The middle layer clearly shows the micro structure of the deformed aluminium.

The microstructure is almost uniform except in some places where there is a pit formed. The bottom layer micro structure clearly indicates the carbon fiber with epoxy matrix. Fracture and pit formation are observed due to the application of the impact load.

From the analysis of the SEM images, it has been noticed that the fiber breakages, fuzzy surface, fiber debondings, fiber pull-out and pits are some of the defects, which are

\section{References}

1. Bosco MAJ, Palanikumar K, Prasad BD and Velayudham A. Analysis on influence of machining parameters on thrust force in drilling GFRP-armor steel sandwich composites. Journal of Composite Materials. 2015; 49(13):1539-1551. http://dx.doi. org/10.1177/0021998314536068.

2. Asundi A and Choi AYN. Fiber metal laminates: an advanced material for future aircraft. Journal of Materials Processing Technology. 1997; 63(1-3):384-394. http://dx.doi.org/10.1016/ S0924-0136(96)02652-0.

3. Cortes P and Cantwell WJ. The prediction of tensile failure in titanium-based thermoplastic fibre-metal laminates. Composites Science and Technology. 2006; 66(13):2306-2316. http://dx.doi. org/10.1016/j.compscitech.2005.11.031.

4. Alderliesten RC and Benedictus R. Fiber/metal composite technology for future primary aircraft structures. In: 48th AIAA/ ASME/ASCE/AHS/ASC Structures, Structural Dynamics, and Materials Conference; 2007; Honolulu. Reston: AIAA; 2007. p. 1-12. http://dx.doi.org/10.2514/6.2007-2404.

5. Chang PY, Yeh PC and Yang JM. Fatigue crack initiation in hybrid boron/glass/aluminium fiber metal laminates. Materials Science and Engineering A. 2008; 496(1-2):273-280. http:// dx.doi.org/10.1016/j.msea.2008.07.041.

6. Vogelesang LB and Vlot A. Development of fibre metal laminates for advanced. Journal of Materials Processing Technology. 2000; 103(1):1-5. http://dx.doi.org/10.1016/S0924-0136(00)00411-8.

7. Alderliesten R. On the development of hybrid material concepts for aircraft structures. Recent Patents in Engineering. 2009; 3(1):25-38. http://dx.doi.org/10.2174/187221209787259893.

8. Krishnakumar S. Fiber metal laminates: the synthesis of metals and composites. Materials and Manufacturing Processes. 1994; 9(2):295-877. http://dx.doi.org/10.1080/10426919408934905.

9. Reyes VG and Cantwell WJ. The mechanical properties of fibermetal laminates based on glass fiber reinforced polypropylene. observed in the composite specimen. And this is due to the application of the load on the specimen.

\section{Conclusion}

In the present investigation, carbon fiber reinforced aluminium sandwich composites are fabricated and their mechanical properties are evaluated. Based on the experimental investigation and analysis, the following conclusions are drawn:

- The tensile strength, flexural strength and the impact strength are observed for 3 different specimen. The tensile strength increases up to certain limit, and then falls due to the variation of metal-fiber laminate.

- The flexural strength also shows the same trend due to two different materials such as fiber and aluminium.

- The fractured surface of the tensile, flexural and impact specimen are analyzed by using scanning electron microscopy (SEM).

- The SEM micrographs indicate debonding, fuzziness, fiber fracture and pit formation due to the application of load.

Composites Science and Technology. 2000; 60(7):1085-1094. http://dx.doi.org/10.1016/S0266-3538(00)00002-6.

10. Vogelesang LB and Vlot A. Development of fiber metal laminates for advanced aerospace structures. Journal of Materials Processing Technology. 2000; 103(10):1-5. http:// dx.doi.org/10.1016/S0924-0136(00)00411-8.

11. Song SH, Byun YS, Ku TW, Song WJ, Kim J and Kang BS. Experimental and numerical investigation on impact performance of carbon reinforced aluminium laminates. Journal of Materials Science and Technology. 2010; 26(4):327-332. http://dx.doi. org/10.1016/S1005-0302(10)60053-9.

12. Xue J, Wang WX, Takao Y and Matsubara T. Reduction of thermal residual stress in carbon fiber aluminium laminates using a thermal expansion clamp. Composites. Part A, Applied Science and Manufacturing. 2011; 42(8):986-992. http://dx.doi. org/10.1016/j.compositesa.2011.04.001.

13. Wang WX, Takao Y, Matsubara T, Uchimura C, Baba S and Higashijima M. Development of galvanic corrosion-resistant CFML based on composite coating. Journal Society of Material Science Japan. 2007; 56(5):420-425 [in Japanese]. http://dx.doi. org/10.2472/jsms.56.420.

14. Lawcock GD, Ye L, Mai YW and Sun CT. Effects of fibre/ matrix adhesion on carbon-fibre-reinforced metal laminatesII. impact behavior. Composites Science and Technology. 1998; 57(12):1621-1628. http://dx.doi.org/10.1016/S02663538(97)00094-8.

15. Jiang N, Novak JP and Fink RL. Fabrication and characterization of carbon: aluinium thermal management composites. In: 26th Annual IEEE: Semiconductor Thermal Measurement and Management Symposium; 2010; Santa Clara. IEEE; 2010. p. 87-92. http://dx.doi.org/10.1109/STHERM.2010.5444308.

16. Lihong S, Cheng L, Guanyu D, Kiet T and Xudong S. Microstructure and mechanical properties of 1050/6061laminated composite processed by accumulative roll bonding. Reviews on Advanced Materials Science Volume. 2013; 33(1):33-37. 
17. George T, Deshpande VS and Wadley HNG. Mechanical response of carbon fiber composite sandwich panels with pyramidal truss cores. Composites. Part A, Applied Science and Manufacturing. 2013; 47:31-40. http://dx.doi.org/10.1016/j. compositesa.2012.11.011.

18. Sun Z, Jeyaraman J, Shi S, Sun S, Hu X and Chen H. Processing and property of carbon-fiber aluminium-foam sandwich with aramid-fiber composite adhesive joints. Journal of Adhesion Science and Technology. 2014; 28(18):1835-1845. http://dx.doi. org/10.1080/01694243.2014.925385.

19. Caprino G, Spataro G and Del Luongo S. Low-velocity impact behavior of fibre glass-aluminium laminates. Composites. Part A, Applied Science and Manufacturing. 2004; 35(5):605-616. http://dx.doi.org/10.1016/j.compositesa.2003.11.003.

20. Khalili SMR, Mittal RK and Kalibar SG. A study of the mechanical properties of steel/aluminium/grp laminates. Materials Science and Engineering A. 2005; 412(1-2):137-140. http://dx.doi. org/10.1016/j.msea.2005.08.016.

21. Afaghi-Khatibi A, Lawcock G, Ye L and Mai Y-W. On the fracture mechanical behaviour of Fibre Reinforced Metal Laminates (FRMLs). Computer Methods in Applied Mechanics and Engineering. 2000; 185(2-4):173-190. http://dx.doi. org/10.1016/S0045-7825(99)00258-3.

22. Xia Y, Wang Y, Zhou Y and Jeelani S. Effect of strain rate on behaviour of carbon fiber reinforced aluminium laminates. Materials Letters. 2007; 61(1):213-215. http://dx.doi.org/10.1016/j. matlet.2006.04.043.

23. Khalili SMR, Mittal RK and Kalibar GS. Astudy of the mechanical properties of steel/aluminium/GRP laminates.
Materials Science and Engineering A. 2005; 412(1-2):137-140. http://dx.doi.org/10.1016/j.msea.2005.08.016.

24. Carrillo JG and Cantwell WJ. Mechnaical properties of a novel fiber-metal laminate based on a polypropylene composite. Mechanics of Materials. 2009; 41(7):828-838. http://dx.doi. org/10.1016/j.mechmat.2009.03.002.

25. Wu G, Tan Y and Yang JM. Evaluation of residual strength of notched fiber metal laminates. Materials Science and Engineering A. 2007; 457(1-2):338-349. http://dx.doi.org/10.1016/j. msea.2006.12.135.

26. Carrillo JG and Cantwell WJ. Scaling effects in the tensile behaviour of fiber-metal laminates. Composites Science and Technology. 2007; 67(7-8):1684-1693. http://dx.doi.org/10.1016/j. compscitech.2006.06.018.

27. Kawai M and Arai Y. Off-axis notched strength of fiber-metal laminates and a formula for predicting anisotropic size effect. Composites. Part A, Applied Science and Manufacturing. 2009; 40(12):1900-1910. http://dx.doi.org/10.1016/j. compositesa.2009.07.014.

28. Iaccarino P, Langella A and Caprino G. Asiplified model to predict the tensile and shear stress-strain behaviour of fibre-glass/aluminium laminates. Composites Science and Technology. 2007; 67(9):1784-1793. http://dx.doi.org/10.1016/j. compscitech.2006.11.005.

29. Botelho EC, Almeida RS, Pardini LC and Rezende MC. Elastic properties of hygrothermally conditioned glare laminate. International Science of Engineering and Technology. 2007; 45(1):163-172. http://dx.doi.org/10.1016/j.ijengsci.2006.08.017. 